\title{
Reply to Letter to the Editor: Re: Robot-assisted gastrojejunal anastomosis does not improve the results of the laparoscopic Roux-en-Y gastric bypass Surg Endosc 25:597-603
}

\author{
Mario Morino • Gitana Scozzari
}

Published online: 20 August 2011

(C) Springer Science+Business Media, LLC 2011

A comparison between a totally robotic laparoscopic Rouxen-Y gastric bypass (LRYGBP) and a standard LRYGBP was not among the objectives of our study, and neither was our objective to compare handsewn vs. robotic sutured laparoscopic anastomoses. The purpose of our study, as clearly stated in its title [1], was to verify whether the introduction of the Da Vinci system in a bariatric program could improve the results of LRYGBP and therefore the results of robotic LRYGBP have been compared with our standard laparoscopic LRYGBP. The results of this study showed that there was no clinical improvement, but operative time was longer and the cost was higher. In our opinion, this was a clear answer to a precisely defined question. Other studies could, and probably should, be designed to answer to the questions proposed by Addeo and Buchs.

With regard to the learning curve issue, in our study laparoscopic and robotic gastric bypass were performed by three different authors (FR, PM, MM) with considerable experience in laparoscopic and robotic surgery in numerous field of digestive surgery. Nevertheless, it is quite paradoxical the importance that Addeo and Buchs attribute to the learning curve in robotic surgery, because the limited learning curve is considered as one of the main advantages of robotic surgery compared with standard laparoscopy [2-4].

\section{References}

1. Scozzari G, Rebecchi F, Millo P et al (2011) Robot-assisted gastrojejunal anastomosis does not improve the results of the laparoscopic Roux-en-Y gastric bypass. Surg Endosc 25:597-603

2. Chang L, Satava RM, Pellegrini CA et al (2003) Robotic surgery: identifying the learning curve through objective measurement of skill. Surg Endosc 17:1744-1748

3. Narazaki K, Oleynikov D, Stergiou N (2006) Robotic surgery training and performance: identifying objective variables for quantifying the extent of proficiency. Surg Endosc 20:96-103

4. Chandra V, Nehra D, Parent R et al (2010) A comparison of laparoscopic and robotic assisted suturing performance by experts and novices. Surgery 147:830-839
M. Morino $(\bowtie) \cdot$ G. Scozzari

Digestive, Colorectal and Minimal Invasive Surgery,

Department of Surgery, University of Torino, Turin, Italy

e-mail: mario.morino@unito.it

G. Scozzari

e-mail: gitanascozzari@gmail.com 